\title{
Percepção entomológica por discentes do Ensino Fundamental em Ciências em vistas a proteção da biodiversidade
}

\author{
Entomological perception by students of Elementary Science in order to protect biodiversity
}

\author{
ALVES $^{1}$, C. A. B.; CAVALCANTE², M. B.; ARRUDA³, L. V.; SOUZA, R. S. ${ }^{4}$ \\ C_belarminoalves@hotmail.com;
}

\begin{abstract}
Resumo
Os insetos são seres que se encontram em maior abundância e com diversas funções no planeta sendo apenas $10 \%$ que prejudica o homem, no entanto, existe ainda uma visão negativa em relação ao mundo dos insetos. A pesquisa analisou a percepção entomológica dos discentes quanto ao conhecimento que possuem sobre os insetos. $\mathrm{O}$ estudo foi realizado através de questionários não estruturados composto por quatro questões para 37 e 35 discentes nas séries de $8^{\circ}$ e $9^{\circ}$ ano respectivamente totalizando 72 discentes na Escola Estadual Ministro José Américo de Almeida na cidade de Areia - PB. Ao analisar os questionários, constatou-se que $84,61 \%$ dos discentes classificaram de maneira correta os organismos pertencentes à classe insecta, e os demais indivíduos "insetos" eram de outras categorias taxonômicas amphibia, arachnida, chilopoda, gastropoda, hirudínea, mammalia, oligochaeta e reptilia. Essa visão pode ser explicada pela hipótese da ambivalência entomoprojetiva, onde os seres humanos tendem a projetar sentimentos de nocividade, periculosidade, irritabilidade, repugnância e menosprezo aos animais determinados culturalmente como "insetos" e classificá-los em uma mesma categoria. Nesse sentido, os discentes ainda tem pouco conhecimento sobre os aspectos positivo dos insetos sendo necessário que os docentes busquem formas para transmitir o tema.
\end{abstract}

Palavras chave: Biodiversidade, Entomologia, Meio ambiente.

\begin{abstract}
Insects are the most abundant beings found and with several functions on the planet, only $10 \%$ of them could harm men, however, there is still a negative view regarding the world of insects. The 1study analyzed the entomological perception of students regarding their knowledge about insects. Thestudy was carried out through unstructured questionnaires composed by four questions for 37 and 35 students in 8th and 9th grade, respectively, totaling 72 students at the Ministro José Américo de Almeida State School, in Areia city - PB. Analyzing the questionnaires, it was noticed that $84.61 \%$ of the students classified in a correct way the organisms which belong to the class insecta, and other individuals "insects" were from other taxonomic categories amphibia, arachnida, chilopoda, gastropoda, hirudínea, mammalia, oligochaeta and reptilia. This view may be explained by the hypothesis of entomoprojective ambivalence, where humans tend to project feelings of harmfulness, dangerousness, irritability, loathing and contempt to animals culturally determined as "insects" and classify them in the same category. This way, the students still have little knowledge about the positive aspects of the insects, being necessary that teachers find ways how to convey the theme.
\end{abstract}

Keywords: Public ensine, Entomology, Environment. 


\section{INTRODUÇÃO}

A classe insecta destaca-se pela sua abundância na natureza, cujo sucesso atribui-se a presença de um exoesqueleto que tem por finalidade proteger os órgãos internos e a presença de asas funcionais que facilita aos insetos: a dispersão, a fuga dos inimigos naturais e a captura de alimentos (BUZZI, 2010). Estes seres são de fundamental importância devido as suas diferentes funções ecológicas que desempenham no ecossistema, uma vez que, agem como herbívoros, decompositores, predadores e parasitóides.

Os insetos são seres que estão interligados ao homem de tal forma que pode-se afirmar, que a humanidade não conseguiria sobreviver sem os insetos, pois o abastecimento de alimentos seria afetado, diversas doenças como a malária e a peste bubônica não teriam controle com a ausência dos mesmos.

Muitos insetos a serem observados são rotulados como maléficos, pois existe uma concepção generalizada de que todos ou pelo menos grande parte dos insetos são prejudiciais, afirmação essa errônea. Pois os insetos em relação ao homem podem ser divididos em três categorias: os insetos úteis; nocivos; e demais insetos que não causam nenhum benefício ou malefício ao homem, porém fazem parte da cadeia alimentar de outros animais (BUZZI, 2010)

Devido a sua grande diversidade, fácil coleta e importância ecológica esses animais podem ser utilizados como bioindidicadores do grau de alteração ambiental, pois fornece informações importantes para conservação, restauração, monitoramento e uso sustentável de recursos naturais (LEWINSOHN et al., 2005; FREITAS et al., 2006).

São frequentes tais perguntas: quantas espécies há no Brasil, nos biomas ou em determinadas áreas? Por que é importante saber isso? A resposta é clara: ninguém sabe, com certeza, o número de espécies existentes; se tem apenas estimativas, especialmente quando se trata de invertebrados.

A relevância do tema baseia-se no fato de que a biodiversidade, além de ser imprescindível para a manutenção da vida na Terra, também é fundamental para atender necessidades básicas do ser humano. Além disso, estes recursos são propriedades do país que os detém e devem ser considerados estratégicos para o desenvolvimento da nação. Deste modo como indica Camargo (2009), as coleções devem ser vistas como bancos de dados fundamentais para o desenvolvimento científico e tecnológico. 
A diversidade de insetos presente no território nacional é imensa considerando o número ainda não descrito que aguardam nas gavetas das nossas coleções cientificas e as enormes lacunas de amostragem na maioria dos biomas brasileiros, podemos considerar que o número real de insetos que habitam o território nacional deve ser dez vezes maior. É importante desmistificar falsas verdades e mudar paradigmas estabelecidos sobre certos grupos da fauna. Existe uma concepção errônea e generalizada de que todos (ou a maioria dos insetos) são prejudiciais.

No entanto, estudos em projetos agrícolas efetuados pela Embrapa Cerrados em cooperação técnica com Japan Internacional Cooperation Agency (JICA) demonstraram que apenas um pequeno percentual dos insetos (8-13\%) eram pragas com alguma importância econômica, portanto é claro a necessidade de mudança conceitual para a quebra de alguns paradigmas nessa área. Nesse sentido, o presente estudo analisou a percepção entomológica dos discentes quanto ao conhecimento que possuem sobre os insetos.

A pesquisa teve objetivo analisar a percepção entomológica dos discentes quanto ao conhecimento que possuem sobre os insetos.

\section{METODOLOGIA}

\section{1 Área de Estudo}

A pesquisa foi realizada na Escola Estadual de Ensino Fundamental e Médio "Ministro José Américo de Almeida", localizada no município de Areia-PB, apresentando uma altitude em torno de 618m acima do nível do mar possuindo clima um Clima tropical com estação seca, o município faz parte da mesorregião do agreste paraibano e da microrregião do Brejo paraibano. Este possui uma extensão territorial de $269 \mathrm{Km}^{2}$ e uma população de 23.829 habitantes (IBGE, 2010), encontrando-se nas coordenadas de $6^{\circ} 57^{\prime} 42^{\prime \prime} \mathrm{S} 35^{\circ} 41^{\prime} 43^{\prime \prime} \mathrm{O}$.

\subsection{Instituição pesquisada}

A Escola Estadual de Ensino Fundamental e Médio "Ministro José Américo de Almeida" pertence à rede Estadual de Ensino, regida pela $3^{\text {a }}$ Gerência Regional de Educação do Estado da Paraíba na cidade de Areia - PB (Foto 01), mantendo o Ensino Fundamental do $6^{\circ}$ ao $9^{\circ}$ ano e o Ensino médio do $1^{\circ}$ ao $3^{\circ}$ ano, sendo os, alunos que foram convidados e participar deste trabalho, os devidamente matriculados no ensino fundamental no $8^{\circ}$ e $9^{\circ}$ ano (quatro turmas), totalizando 72 (setenta e dois) alunos. 


\subsection{Levantamento sobre Percepção Entomológica}

A pesquisa contou com a participação de 72 discentes do Ensino Fundamental II abrangendo as séries do $8^{\circ}$ e $9^{\circ}$ anos com faixa etária entre 13 e 17 anos, sendo que $60 \%$ destes discentes são do gênero masculino e $40 \%$ do gênero feminino. A aplicação dos questionários não estruturados, contendo questões subjetivas sobre os insetos (Anexo I), Após a aplicação dos questionários os dados obtidos passaram por um padrão de contagem e atribuição de percentual, sendo utilizada para a representação dos dados gráficos.

\section{RESULTADOS E DISCUSSÃO}

Dos 72 alunos amostrados sobre o que são insetos apenas $44 \%$ responderam de maneira correta total ou parcialmente, enfatizando em suas respostas, que estes animais são pequenos invertebrados que voam de suma importância para o planeta. Logo, muitos dos entrevistados erraram (39\%) quando fora perguntado e $17 \%$ não souberam responder (Gráfico 1).

\section{Percepção Entomológica}

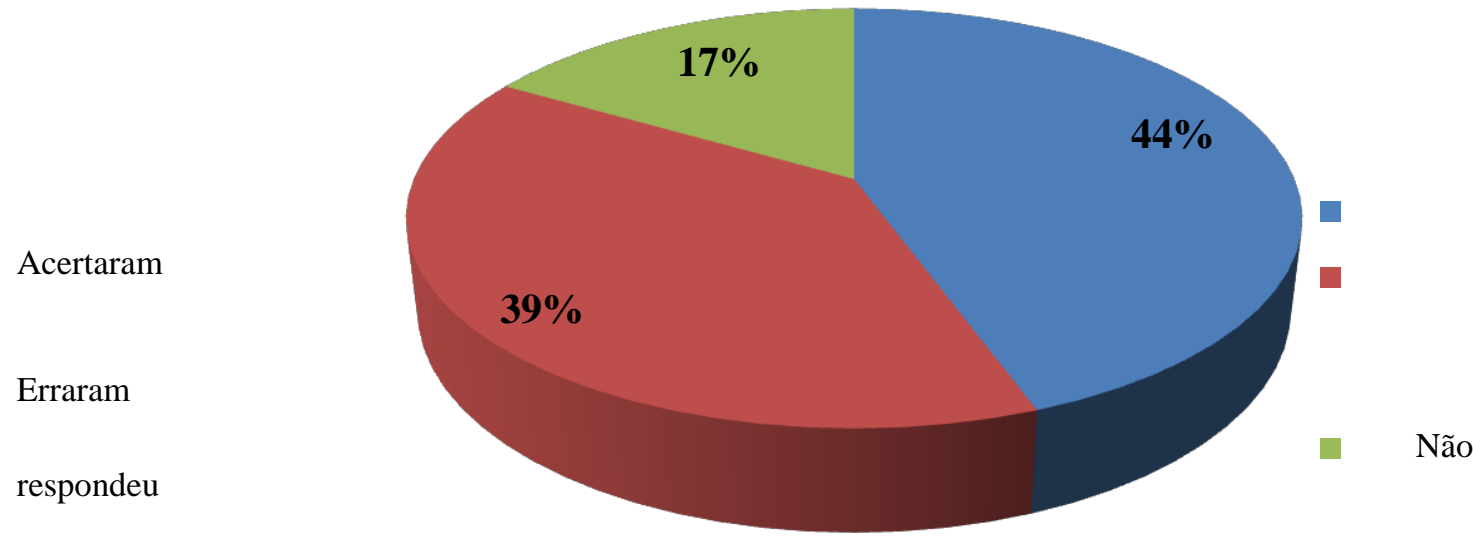

Gráfico 1- Resposta dos alunos quando indagados sobre o que são insetos.

A primeira questão fez perceber a realidade da rede pública de ensino estudada evidenciando a necessidade do enfoque do tema dentro da sala de aula pelos docentes. Além disso, é fundamental que os professores busquem métodos para trabalhar com estes seres no 
âmbito escolar como audiovisual, coleções entomológicas e aula de campo, enfatizando sua importância no meio ambiente. Os resultados do referido trabalho corroboram com os de Modro et al. (2009), ao constatarem também que os alunos entrevistados, definem os "insetos" como seres pequenos $(61 \%)$, perigosos $(28 \%)$ ou nojentos $(24 \%)$.

O Gráfico 2, demonstra que $42 \%$ dos discentes não atribuíram importância alguma aos insetos, $40 \%$ dos discentes consideram os insetos muito importantes pois afirmam que esses seres fazem parte da cadeia trófica de outros animais que por conseguinte, a sua presença na natureza mantém o ecossistema equilibrado, porém $18 \%$ dos discentes consideram que os insetos são pouco importantes.

A importância dos insetos conforme os entrevistados vêm nos alertar da falta de conhecimento dos alunos quanto aos insetos no âmbito escolar, estes animais invertebrados são de grande importância à manutenção do planeta. Com isso, é necessário que os docentes realizem práticas educacionais que enfatizem a importância dos insetos no ecossistema e as ações funções desempenhadas pelos discentes. Esses resultados assemelham aos de Silva et al. (2009), que ao fazer o mesmo questionamento, os discentes atribuíram a importância dos insetos as diversas funções desempenhadas no equilíbrio do ecossistema, na cadeia trófica e na saúde humana.

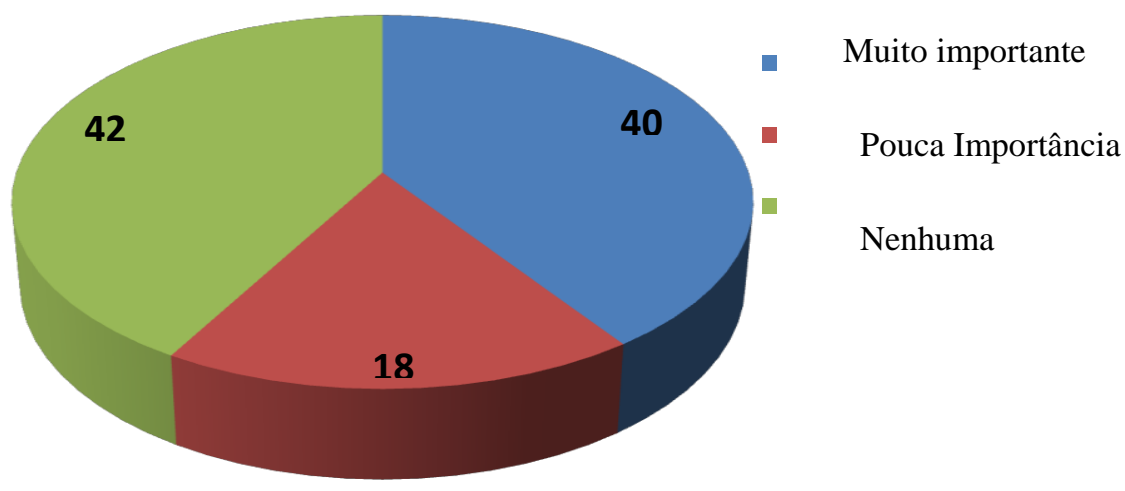

Gráfico 2 - A importância dos insetos para os discentes

Analisando o Gráfico 3, observou-se que quando os discentes foram indagados sobre a sua reação ao observar um inseto $30 \%$ dos responderam que os matam, $29 \%$ disseram que 
depende do inseto, $15 \%$ sentem medo, $7 \%$ não responderam,7\% observam o comportamento, $6 \%$ sentem nojo e $3 \%$ reagem de forma normal e os outros $3 \%$ liberam os insetos na natureza.

Quanto á reação dos alunos perante a um inseto observou-se que os mesmos tratam esses animais com desprezos e nojo confirmando o sentimento de querer matá-los, imediatamente. Isso pode ser explicado pela questão cultural, no entanto, devem-se os profissionais da área de educação buscar mudar essa concepção errônea que estes alunos têm em relação aos insetos.

Assim pesquisas realizadas na por Modro et al. (2009), constatou que a principal reação dos discentes ao observar um inseto é matá-lo e, também por Costa-Neto (2004), vendo o modo como a maioria das sociedades percebe e se expressa com relação tanto aos próprios insetos quanto aos animais não insetos, identificando-os como "insetos", evidenciam as atitudes, os sentimentos de desprezo, medo e aversão que os seres humanos geralmente demonstram pelos invertebrados.

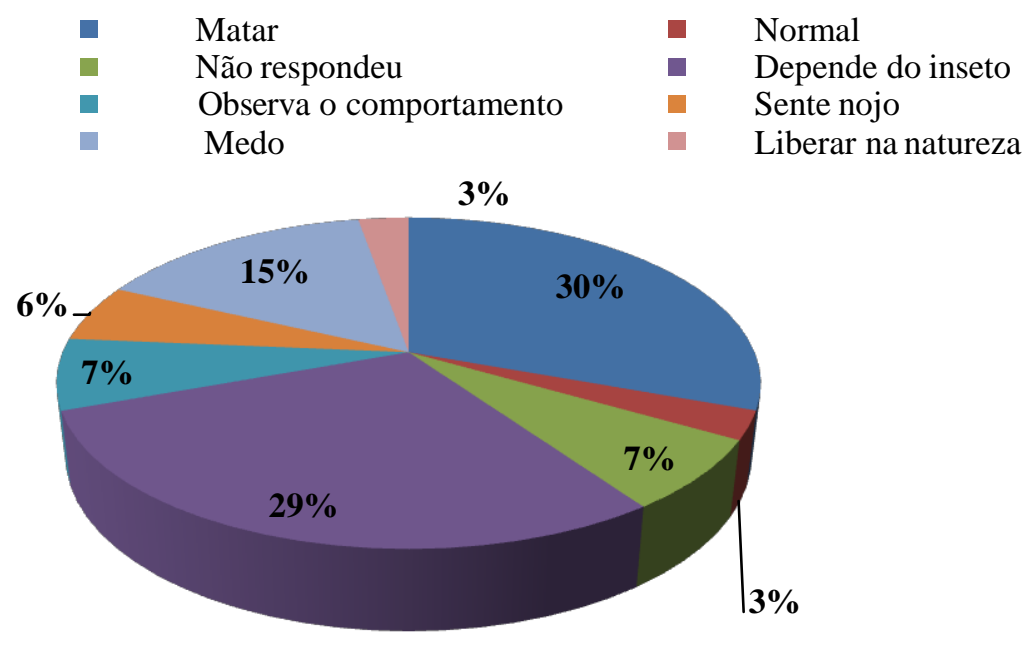

Gráfico 3 - Reação dos discentes ao ver um inseto.

Na Tabela 1, quando os discentes foram questionados a respeito dos insetos que conhecem, a maioria dos seres vivos citados pertence à classe Insecta $(84,61 \%)$ e os outros considerados por eles "insetos", pertencem às classes do Reino Animalia: Amphibia (1,03\%), 
Arachnida (7,69\%), Gastropoda (0,21\%), Hirudinea (0,21\%), Mammalia (1,66\%), Oligochaeta $(2,49 \%)$ e Reptilia $(1,45 \%)$.

A indagação ao que seria um "inseto" mostrou que houve uma concepção equivocada quando fora verificado nos formulários sobre o objeto de estudo. Ficou evidente que é questão cultural, ou seja, passa de pais para filhos e/ou localidade, tendo em vista, que os mesmos podem até vê em sala de aula, contudo não se atentam em distinguir o que seria um inseto.

Esta observação no presente estudo é similar aos de Modro et al. (2009), quando pesquisaram que a maior parte dos organismos vivos percebidos como "insetos", pertencem a classe Insecta $(82,75)$ e os demais seres citados a outras classes taxonômicas. Isso pode ser explicado em decorrência da ambivalência entomoprojetiva, onde os seres humanos tendem a projetar sentimentos de nocividade, periculosidade, irritabilidade, repugnância e menosprezo aos animais determinados culturalmente como "insetos" e classificá-los em uma mesma categoria (COSTA-NETO, 1999).

Tabela 1. Seres vivos percebidos como "insetos" por discentes do ensino público em Areia-PB

\begin{tabular}{|c|c|c|c|}
\hline Reino * & Classe* & Etnocategoria Taxonômica & Citações (\%) \\
\hline \multirow[t]{29}{*}{ Animalia } & Amphibia & Rã & 0,21 \\
\hline & & Sapo & 0,83 \\
\hline & Arachnida & Aranha & 4,16 \\
\hline & & Caranguejeira & 0,41 \\
\hline & & Carrapato & 2,50 \\
\hline & & Escorpião & 0,62 \\
\hline & Chilopoda & Centopeia & 0,62 \\
\hline & Gastropoda & Lesma & 0,21 \\
\hline & Hirudinea & Sanguessuga & 0,21 \\
\hline & Insecta & Abelha & 4,78 \\
\hline & & Arapuá & 0,21 \\
\hline & & Barbeiro & 0,83 \\
\hline & & Barata & 12,70 \\
\hline & & Besouro & 1,04 \\
\hline & & Bicho-pau & 0,21 \\
\hline & & Bicho da seda & 0,21 \\
\hline & & Borboleta & 6,03 \\
\hline & & Cavalo do cão & 0,62 \\
\hline & & Cigarra & 0,83 \\
\hline & & Cupim & 1,66 \\
\hline & & Escaravelho & 0,21 \\
\hline & & Esperança & 0,41 \\
\hline & & Formiga & 8,52 \\
\hline & & Gafanhoto & 5,00 \\
\hline & & Grilo & 6,65 \\
\hline & & Joaninha & 1,04 \\
\hline & & Lagarta & 1,87 \\
\hline & & Louva-deus & 0,41 \\
\hline & & Mosca & 11,85 \\
\hline
\end{tabular}




\begin{tabular}{|c|c|c|}
\hline & \\
\hline & Muriçoca & 4,16 \\
\hline & Mané mago & 0,21 \\
\hline & Maribondo & 2,50 \\
\hline & Mariposa & 0,21 \\
\hline & Maruim & 0,41 \\
\hline & Mosquito da dengue & 1,25 \\
\hline & Mosquito & 4,57 \\
\hline & Percevejo & 0,21 \\
\hline & Pernilongo & 1,87 \\
\hline & Piolho & 0,62 \\
\hline & Pulga & 0,62 \\
\hline & Rola bosta & 0,21 \\
\hline & Serra-pau & 0,21 \\
\hline & Tanajura & 0,62 \\
\hline & Traça & 0,21 \\
\hline & Vagalume & 0,41 \\
\hline & Varejeira & 0,41 \\
\hline & Vespa & 0,21 \\
\hline & Zangão & 0,62 \\
\hline \multirow[t]{2}{*}{ Mammalia } & Morcego & 0,83 \\
\hline & Rato & 0,83 \\
\hline Oligochaeta & Minhoca & 2,50 \\
\hline \multirow[t]{4}{*}{ Reptilia } & Cobra & 0,41 \\
\hline & Jiboia & 0,21 \\
\hline & Lagarto & 0,41 \\
\hline & Lagartixa & 0,41 \\
\hline
\end{tabular}

* Nomenclatura cientifica.

Para mensuração da percentagem foram somados.

\section{CONSIDERAÇÕES FINAIS}

O conhecimento dos alunos sobre a classe Insecta é rudimentar, havendo a necessidade dos docentes trabalharem tanto a identificação, quanto a importância deste táxon com os alunos, buscando desmistificar o paradigma que o alunado tem sobre o mundo dos invertebrados. É necessária a utilização de métodos práticos (como a realização de aulas de campo; trilhas e visitas em matas; ações socioeducativas; educação ambiental, etc.) que juntamente com as aulas teóricas sejam instrumentos eficazes para o conhecimento dos discentes sobre a fauna (insetos), uma vez que essas metodologias despertam a atenção do aluno e atuam de forma positiva no seu aprendizado.

De modo geral, a escola deverá implantar pequenos laboratórios de entomologia, com o intuito de garantir o maior aproveitamento teórico e prático. 


\section{REFERÊNCIAS}

CAMARGO, A. J. A. Coleções zoológicas: importância estratégica para o país e para o agronegócio em particular. Planaltina, DF: Embrapa Cerrados, 2009. Disponível em <http://www.cpac.embrapa.br/noticias/artigosmidia/publicados/119/>. Acesso em: 24 fev. 2013.

COSTA NETO, E.M. Etnocategoria “inseto" e a hipótese da ambivalência projetiva. Acta Biológica Leopoldensia, v. 21, n. 1, p. 7-14, 1999.

COSTA NETO, E.M. Os insetos que "ofendem": Artropodoses na visão dos moradores da região da Serra da Jibóia,Bahia,Brasil. Sitientibus, Série Ciências Biológicas, 4 (1/2), p. 59-68, 2004. BUZZI, Z. J. Entomologia didática, 5. ed. Curitiba: UFPR, 2010.

FREITAS, A. V.L.; LEAL, I.R.; UEHARA-PRADO, M.; IANNUZI, L. Insetos como indicadores de conservação da paisagem. In: Biologia da conservação: essências, cap.15, RiMa Editora,São Carlos,p. 357-384,2006.

INSTITUTO BRASILEIRO DE GEOGRAFIA E ESTATÍSTICA - IBGE. Mapa - Paraíba 2013.Disponível em: http://www.ibge.gov.br. Acesso em: 10/03/2013.

INSTITUTO BRASILEIRO DE GEOGRAFIA E ESTATÍSTICA - IBGE. Cidades - Paraíba 2013. Disponível em: < http://www.ibge.gov.br>. Acesso em 10/03/2013.

LEWINSOHN, T. M.; FREITAS, A.V.L.; PRADO, P.I. Conservation of terrestrial invertebrates and their habitats in Brazil. In: Conservation Biology,p.640-645,2005.

MODRO, A.F.H.; COSTA, M.S.; MAIA, E.; ABURAYA, F.H. Percepção entomológica por docentes e discentes do município de Santa Cruz do Xingu, Mato Grosso, Brasil. Biotemas, v. 22, n. 2, p. 153-159, 2009.

SILVA, M.L.L.S.; OLIVEIRA, C.R.F.; MATOS, C.H.C.; BEZERRA, Y.B.S.; FERRAZ, C.S. Redescobrindo o mundo dos insetos nas escolas do sertão do Pajeú. In: IX JORNADA DE ENSINO, PESQUISA E EXTENSÃO, 2009, Recife-PE. Resumos. Recife-PE: JEPEX, 2009.

Recebido em: 15/08/2018

Aceite para publicação em: 05/11/2018 